\title{
Morphological and Molecular Characteristics of Clinostomid Metacercariae from Korea and Myanmar
}

\author{
Eun Jeong Won ${ }^{1}$, Yu Jeong Lee', Moon-Ju Kim¹, Jong-Yil Chai ${ }^{2,3} \mathbb{\oplus}$, Byoung-Kuk Na ${ }^{4}$, Woon-Mok Sohn ${ }^{4, *} \mathbb{C}$ \\ ${ }^{1}$ Departments of Parasitology and Tropical Medicine, Chonnam National University Medical School, Gwangju 61469, Korea, ${ }^{2}$ Institute of Parasitic \\ Diseases, Korea Association of Health Promotion, Seoul 07649, Korea; ${ }^{3}$ Department of Tropical Medicine and Parasitology, Seoul National University

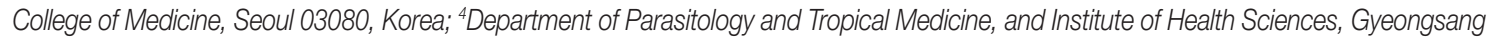 \\ National University College of Medicine, Jinju 52727, Korea
}

\begin{abstract}
Morphological and molecular characterization of clinostomid metacercariae (CMc) was performed with the specimens collected in fish from Korea and Myanmar. Total 6 batches of clinostomid specimens by the fish species and geographical localities, 5 Korean and 1 Myanmar isolates, were analyzed with morphological (light microscopy and SEM) and molecular methods (the cytochrome $c$ oxidase 1 gene and internal transcribed spacer $1 / 5.8 \mathrm{~S}$ rRNA sequence). There were some morphological variations among CMc specimens from Korea. However, some morphometrics, i.e., the size of worm body and each organ, ratio of body length to body width, and morphology of cecal lumens, were considerably different between the specimens from Korea and Myanmar. The surface ultrastructures were somewhat different between the specimens from Korea and Myanmar. The CO1 sequences of 5 Korean specimens ranging 728-736 bp showed 99.6$100 \%$ identity with Clinostomum complanatum (GenBank no. KM923964). They also showed 99.9-100\% identity with C. complanatum (FJ609420) in the ITS1 sequences ranging 692-698 bp. Meanwhile, the ITS1 sequences of Myanmar specimen showed 99.9\% identity with Euclinostomum heterostomum (KY312847). Five sequences from Korean specimens clustered with the $C$. complanatum genes, but not clustered with Myanmar specimens. Conclusively, it was confirmed that $\mathrm{CMc}$ from Korea were morphologically and molecularly identical with $C$. complanatum and those from Myanmar were $E$. heterostomum.
\end{abstract}

Key words: Clinostomum complanatum, Euclinostomum heterostomum, clinostomid fluke, metacercaria, morphology, molecular analysis, Korea, Myanmar

\section{INTRODUCTION}

Members of the genus Clinostomum Leidy, 1856 (Digenea: Clinostomidae) are laryngeal flukes in avian and mammalian hosts. A variety of species have been reported in the world, but the type species, Clinostomum complanatum, is most widely distributed in the Old Continent and known as the human-infecting species. More than 25 human cases have been mainly reported in Japan and the Republic of Korea (Korea) [1-8]. Especially in Korea, several studies on this fluke were performed since the first report of a human case in 1994 [3]. Chung et al. $[9,10]$ reported 12 species of freshwater fish as the second intermediate hosts and a species of freshwater snail, the Korean big-ear radix (Radix auricularia coreana) as the first intermediate

\footnotetext{
- Received 31 August 2020, revised 18 October 2020, accepted 13 November 2020. *Corresponding author (wmsohn@gnu.ac.kr) (C) 2020, Korean Society for Parasitology and Tropical Medicine This is an Open Access article distributed under the terms of the Creative Commons Attribution Non-Commercial License (https://creativecommons.org/licenses/by-nc/4.0) which permits unrestricted non-commercial use, distribution, and reproduction in any medium, provided the original work is properly cited.
}

host of C. complanatum. Rim et al. [11] detected C. complanatum metacercariae (CcMc) in 2 fish species, i.e., Pseudorasbora parva and Squalidus chankaensis tsuchigae, from Taewha-gang ('gang' means river) and Hyeongsan-gang. Sohn et al. [12] also reported 2 fish species, Punctungia herzi and Hemibarbus longirostris, from Chatan-cheon (a stream of Hantan-gang) in Yeoncheon-gun (gun=county), Gyeonggi-do (do=province), as the second intermediate hosts of this fluke. Recently, Sohn et al. [13] broadly surveyed the infection status with CcMc in fish from the water systems of Nakdong-gang in Korea.

More than 50 species have been reported as the members of the genus Clinostomum, however, it is quite controversial in their taxonomic validity. The identification of Clinostomum species was mainly done on the basis of morphological features of the metacercariae and/or the adult worms from the definitive hosts in the past. Due to the high degree of morphological variability within the same batches of samples, this fluke group has been subjected to taxonomic revisions [14-16]. The application of molecular technics together with the morphological studies enables to clarify the distinct taxonomic 
position within this fluke group. Dzikowski et al. [17] differentiated C. complanatum and C. marginatum, of which taxonomic validity has long been debated by many workers, on the basis of $18 \mathrm{~S}$ rRNA sequences. After that, the internal transcribed spacer (ITS1 and ITS2) regions or the mitochondrial gene cytochrome $c$ oxidase I (CO1) also have been introduced to discriminate the species of clinostomid flukes [18-20]. In Korea, Chung et al. [9] described the morphological characteristics of CcMc collected in fish from an enzootic focus of this trematode, in Uiseong-gun, Gyeongsangbuk-do, and adults recovered from the pharynx of an experimental chick. Except for the descriptions of Chung et al. [9], no other morphometric approaches for this fluke group have been attempted in Korea. It is also questionable that every Clinostomum specimens collected in various species of fish from various geographical regions of Korean peninsula are CcMc. Moreover, there is no available information on the clinostomid fluke in Myanmar. Therefore, we intended to describe the morphological and molecular characteristics of Korean clinostomid isolates, and to compare them with a Myanmar isolate.

\section{MATERIALS AND METHODS}

\section{Morphological observation}

We collected numerous clinostomid metacercariae (CMc) in a variety of fish species from streams, rivers, and lakes in Korea $[13,21]$. Among them, some samples were more or less morphologically different and they were tentatively divided into 3 types. Type A CMc were collected in Squalidus japonicus koreanus from Yangcheon (stream of Gyeongho-gang) in Sancheonggun, Gyeongsangnam-do. Type B was detected in Carassius auratus from Nakdong-gang in Sangju-si, Gyeongsangbuk-do. Type C was found in C. auratus from Songji-ho ('ho' means lake) in Goseong-gun, Gangwon-do. Each 10 specimens in 3 types were used for light microscopic observations. In June 2018, we also collected total 94 CMc in 2 fish species, Channa sp. and Anabas testudineus, from Yangon, Myanmar. Most of CMc specimens were detected in an unidentified snakehead fish, Channa sp. Among them, 10 samples were used for light microscopic observations.

Each 10 CMc specimens in 4 groups were fixed with 10\% neutral buffered formalin under the cover glass pressure, stained with Semichon's acetocarmine, and observed their morphological characteristics and differential indices under a light microscope with a micrometer. To observe the surface ul- trastructure, some CMc samples from Korea and Myanmar were washed several times with $0.2 \mathrm{M}$ cacodylate buffer $(\mathrm{pH}$ 7.2 ) and fixed with $2.5 \%$ glutaraldehyde at $4^{\circ} \mathrm{C}$. After washing 3 times with the same buffer, they were dehydrated through a graded alcohol series (50\%, 70\%, 80\%, 90\%, 95\%, and absolute alcohol), dried with hexamethyldisilazane, coated (JFC$1100 \mathrm{E}$ ion sputtering device) with gold, and observed with a scanning electron microscope (Philips XL-30S) at $15 \mathrm{kV}$ accelerating voltage.

We basically measured the body length (BL) and width (BW), the size of oral sucker (OS) and ventral sucker (VS), and the distance between 2 suckers. Then, we also calculated the ratio of BL/BW, VSW/OSW, and VSW/BW as the differential indices of $\mathrm{CMc}$. Measurements and scales are given in $\mu \mathrm{m}$.

\section{Molecular analysis}

Total 5 batches of Korean samples (Isolate No. 1-5), i.e., CMc (Isolate No. 1 and 2) in Squalidus japonicus coreanus and $S$. gracilis majimae from Yangcheon in Sancheong-gun, Gyeongsangnam-do, Acheilognathus gracilis (Isolate No. 3) from Cheokgwacheon in Ulju-gun, Ulsan Metropolitan City, C. auratus (Isolate No. 4) from Nakdong-gang in Sangju-si, and S. japonicus coreanus (Isolate No. 5) from Wicheon in Gunwigun, Gyeongsangbuk-do, and 1 Myanmar sample (Isolate No. 6) in Channa sp. from Yangon, were used for molecular analyses. Genomic DNA was extracted from each ethanol-preserved CMc using the QIAamp DNA Mini Kit (Qiagen, Hilden, Germany), according to the manufacturer's protocol, and used as a template for PCR. The newly designed primers, CC_CO1/F (5'-GCCGGGATAGGTTGAACTTT-3') and CC_CO1/R (5'TGAAAATGGGCAATCACAAA-3'), were used for the amplification $\mathrm{CO} 1$ gene. PCR was performed in $15 \mu \mathrm{l}$ reaction mixtures containing $1 \mu \mathrm{l}$ template, $200 \mu \mathrm{M}$ of each dNTP, $0.2 \mu \mathrm{M}$ of each primer, $0.3 \mathrm{U}$ of Ex Taq polymerase (TaKaRa, Shiga, Japan) and manufacturer-supplied reaction buffer. The PCR cycling conditions consisted of 40 cycles of denaturation at $94^{\circ} \mathrm{C}$ for $30 \mathrm{sec}$, annealing at $50^{\circ} \mathrm{C}$ for $40 \mathrm{sec}$, and extension at $72^{\circ} \mathrm{C}$ for $90 \mathrm{sec}$. The DNA region comprising of 18S rRNA, ITS1, and 5.8S rDNA was amplified by PCR using primers BD1_F (5'-GTCGTAACAAGGTTTCCGTA-3') and 5.8S_R1 (5'-CGATGTTCAAAGCA GTATGC-3') [22]. PCR was carried out in $25 \mu \mathrm{l}$ of total volume, which contained $3 \mu \mathrm{l}$ of DNA solution (20-40 ng), Smart $2 \times$ PCR premix Taq (Solgent, Daejeon, Korea), and $2 \mu \mathrm{l}$ of each primer. The mixture was undergone initial denaturation at $94^{\circ} \mathrm{C}$ for $3 \mathrm{~min}$, followed by 45 cycles of denatur- 
ation at $94^{\circ} \mathrm{C}$ for $40 \mathrm{sec}$, annealing at $55^{\circ} \mathrm{C}$ for $45 \mathrm{sec}$, and extension at $72^{\circ} \mathrm{C}$ for $1 \mathrm{~min}$ with a final extension at $72^{\circ} \mathrm{C}$ for 5 min [23]. The PCR products were sent to Macrogen (Seoul, Korea) for direct sequencing using the PCR primers listed above. The chromatograms of both sequences were trimmed manually and assembled using SeqMan software (DNASTAR, Madison, Wisconsin, USA). The assembled sequences were compared with Clinostomum species sequences deposited in GenBank using blast searches. The phylogenetic relationships among the sequences were inferred using neighbor-joining (NI) analysis with Geneious software (11.1.3) based on Tamu-
ra-Nei genetic distance model. Bootstrap analysis was performed with 3,000 replications.

\section{RESULTS}

\section{Light microscopic findings (Table 1)}

Type A Korean CMc (Fig. 1A), typical form, body stout, more or less blunt in both ends, slightly constricted in acetabular level, 5,300-7,725 (6,158 in average) long and 1,400$1,875(1,675)$ wide in anterior $1 / 3$ level. The ratio of body length/body width 2.97-4.80 (3.73). Oral sucker small 320-

Table 1. Comparative dimensions ${ }^{a}$ of clinostomid metacercariae (CMc) in fish from Korea and Myanmar (unit: $\left.\mu \mathrm{m}\right)$

\begin{tabular}{|c|c|c|c|c|}
\hline \multirow{2}{*}{ Organs } & \multicolumn{3}{|c|}{ Korean $\mathrm{CMc}^{\mathrm{b}}$} & \multirow{2}{*}{ Myanmar $\mathrm{CMc}^{\mathrm{c}}$} \\
\hline & Type A & Type B & Type C & \\
\hline Body length (BL) & $5,300-7,725(6,158)$ & $3,700-7,600(5,728)$ & $4,375-5,850(4,958)$ & $6,550-8,950(7,675)$ \\
\hline Body width (BW) & $1,400-1,875(1,675)$ & $1,100-1,975(1,510)$ & $2,000-2,300(2,203)$ & $2,125-3,375(2,778)$ \\
\hline Ratio of BL/BW & 2.97-4.80 (3.73) & 2.53-4.66 (3.89) & 1.97-2.72 (2.26) & 2.46-3.12 (2.78) \\
\hline Oral sucker (OSL) & $320-400$ (360) & $270-350(314)$ & $280-380(311)$ & $380-500$ (443) \\
\hline Oral sucker (OSW) & $360-500$ (433) & $320-420(381)$ & $360-460(407)$ & $500-570(543)$ \\
\hline Ventral sucker (VSL) & $760-950$ (901) & $740-990(806)$ & $810-980$ (908) & $1,030-1,400(1,232)$ \\
\hline Ventral sucker (VSW) & $760-960(900)$ & $740-930(794)$ & $770-990(900)$ & $1,020-1,400(1,200)$ \\
\hline VSW/OSW & $1.70-2.29(2.09)$ & $1.88-2.31(2.06)$ & $1.89-2.43$ (2.22) & $1.92-2.50(2.21)$ \\
\hline Distance between suckers & $480-900$ (652) & $350-780$ (599) & $370-570(458)$ & $550-800(655)$ \\
\hline VSW/BW & $0.47-0.64(0.54)$ & $0.42-0.67(0.54)$ & $0.36-0.50(0.41)$ & $0.40-0.51(0.43)$ \\
\hline
\end{tabular}

${ }^{a}(\mathrm{~L})$ : length; $(\mathrm{W})$ : width; unit is $\mu \mathrm{m} .{ }^{\mathrm{b}}$ Type A: collected in Squalidus japonicus koreanus from Yang-cheon in Sancheong-gun, Gyeongsangnam-do; Type B: in Carassius auratus from Nakdong-gang in Sangju-si, Gyeongsangbuk-do; Type C: in C. auratus from Songji-ho in Goseong-gun, Gangwon-do. In Channa sp. from Yangon, Myanmar.

A

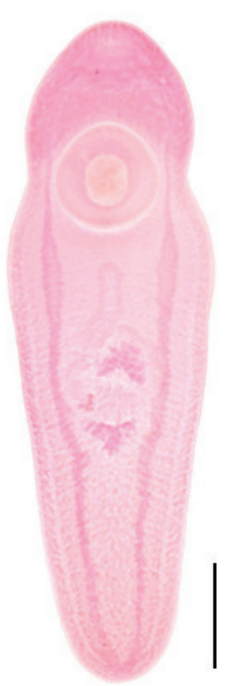

B

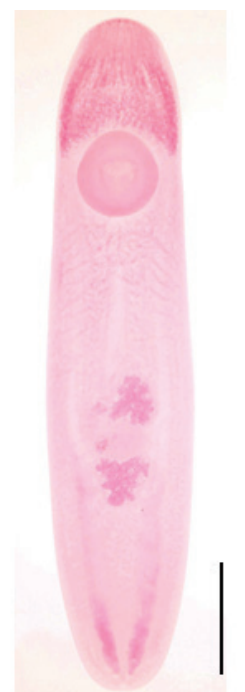

C

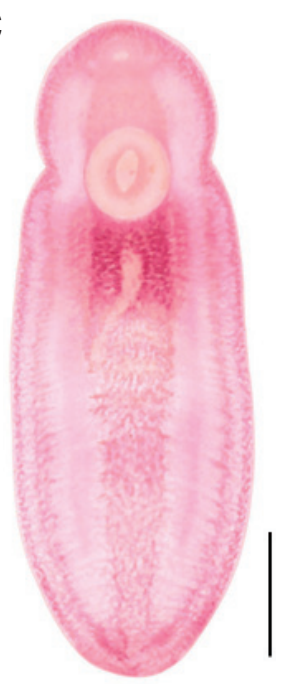

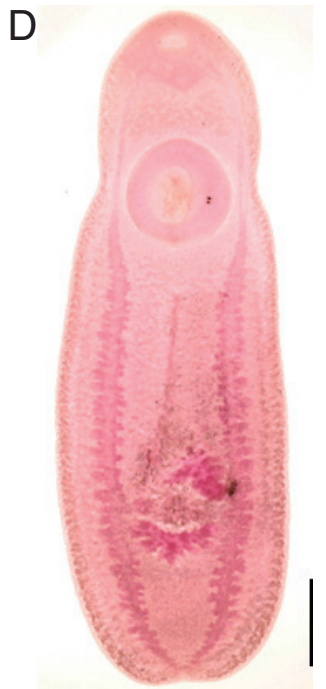

Fig. 1. Light microscopic findings of clinostomid metacercariae (CMc) collected in fish from Korea and Myanmar. (A) Type A CMc collected from Squalidus japonicus coreanus in Yang-cheon, Sancheong-gun, Gyeongsangnam-do. (B) Type B CMc in Carassius auratus from Nakdong-gang in Sangju-si, Gyeongsangbuk-do. (C) Type C CMc in C. auratus from Songji-ho in Goseong-gun, Gangwon-do. (D) CMc detected in snakehead, Channa sp., from Yangon, Myanmar. Scale bar is $1 \mathrm{~mm}$. 
400 (360) by 360-500 (433) in size. Pharynx not observed. Ventral sucker larger than oral sucker, $760-950$ (901) by 760960 (900) in size. The ratio of ventral sucker width/oral sucker width 1.70-2.29 (2.09). Intestinal ceca run laterally to posterior end of the body with smooth thin wall and folded lumen (Fig. 2A). Primordia of genital organs, an ovary and 2 testes, frequently observed in posterior $1 / 3$ median portion. Distance between 2 suckers 480-900 (652). The ratio of ventral sucker width/body width 0.47-0.64 (0.54).

Type B Korean CMc (Fig. 1B), slender form, more or less blunt in both ends, no constrictions, 3,700-7,600 (5,728 in average) long and 1,100-1,975 $(1,510)$ wide in posterior $1 / 3$ level. The ratio of body length/body width 2.53-4.66 (3.89). Oral sucker small 270-350 (314) by 320-420 (381) in size. Pharynx not observed. Ventral sucker larger than oral sucker, $740-990$ (806) by 740-930 (794) in size. The ratio of ventral sucker width/oral sucker width 1.88-2.31 (2.06). Intestinal ceca run laterally to posterior end of the body with smooth thin wall and folded lumen (Fig. 2A). Primordia of genital organs, an ovary and 2 testes, frequently observed in posterior $1 / 3$ median portion. Distance between 2 suckers 350-780 (599). The ratio of ventral sucker width/body width 0.42-0.67 (0.54).

Type C Korean CMc (Fig. 1C), plump form, body stout and tongue-shaped, blunt in both ends, slightly constricted at acetabular level, 4,375-5,850 (4,958 in average) long and 2,000$2,300(2,203)$ wide in posterior $1 / 3$ level. The ratio of body length/body width 1.97-2.72 (2.26). Oral sucker small 280380 (311) by 360-460 (407) in size. Pharynx not observed. Ventral sucker larger than oral sucker, $810-980$ (908) by 770990 (900) in size. The ratio of ventral sucker width/oral sucker width 1.89-2.43 (2.22). Intestinal ceca run laterally to posterior end of the body with smooth thin wall and folded lumen (Fig. 2A). Primordia of genital organs, an ovary and 2 testes, frequently observed in posterior $1 / 3$ median portion. Distance between 2 suckers 370-570 (458). The ratio of ventral sucker width/body width 0.36-0.50 (0.41).

Myanmar CMc (Fig. 1D), body stout and plump, blunt in both ends, slightly constricted in acetabular level, 6,550-8,950 $(7,675$ in average) long and 2,125-3,375 $(2,778)$ wide in posterior $1 / 3$ level. The ratio of body length/body width 2.46-3.12 (2.78). Oral sucker small 380-500 (443) by 500-570 (543) in size. Pharynx not observed. Ventral sucker larger than oral sucker, $1,030-1,400(1,232)$ by 1,020-1,400 $(1,200)$ in size. The ratio of ventral sucker width/oral sucker width 1.92-2.50
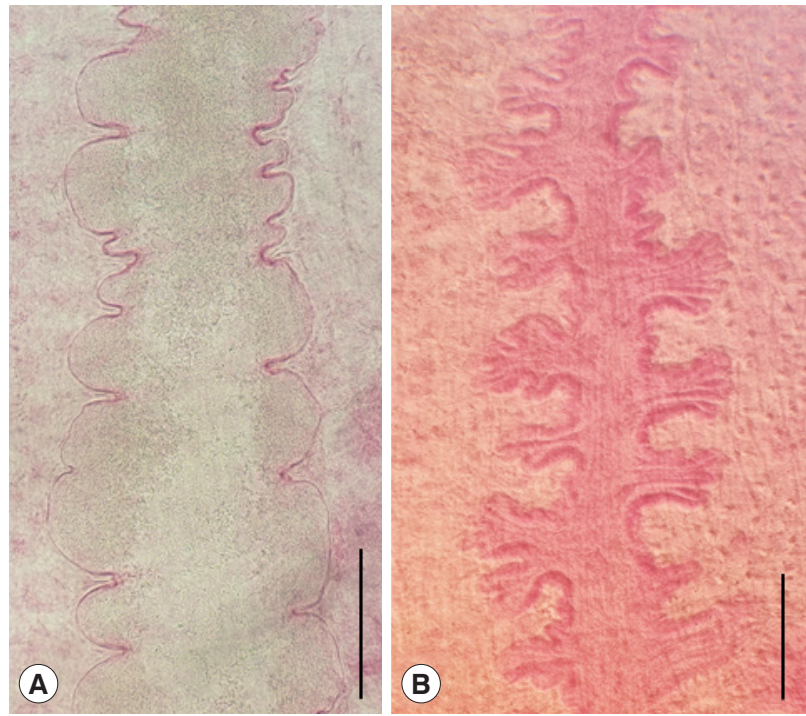

Fig. 2. Intestinal ceca of clinostomid metacercariae (CMc). (A) Korean $\mathrm{CMc}$ with smooth thin wall and folded lumen. (B) Myanmar CMc with relatively thick wall and bilaterally branched lumen. Scale bar $=200 \mu \mathrm{m}$.

(2.21). Intestinal ceca run laterally to posterior end of the body with relatively thick wall and bilataerally branched lumen (Fig. 2B). Primordia of genital organs, an ovary and 2 testes, frequently observed in posterior $1 / 3$ median portion. Distance between 2 suckers 550-800 (655). The ratio of ventral sucker width/body width 0.40-0.51 (0.43).

\section{SEM findings}

Korean CMc were elongated and somewhat stout, ventrally curved and had the largest width at acetabular level (Fig. 3A, B). Oral sucker subterminal, and somewhat smaller than ventral sucker. Ventral sucker located at anterior $1 / 3$ level of body, and had lots of dome-shaped sensory papillae on it's rim (Fig. 3C). Tegumental spines were not seen, but dome-shaped sensory papillae were sparsely distributed on the whole ventral tegument (Fig. 3D). Numerous stratified spinous processes with a single tip were distributed on the whole dorsal tegumental surface (Fig. 3E, F).

Myanmar CMc were somewhat stout, ventrally curved, and had an attenuated anterior end and the largest width in the middle of the body (Fig. 4A, B). Oral sucker subterminal, somewhat smaller than ventral sucker and had lots of domeshaped sensory papillae on it's rim and adjacent tegumental area (Fig. 4C). Ventral sucker located at anterior 1/5 level of body, and had lots of dome-shaped sensory papillae on it's rim (Fig. 4D). Genital pore located at 2/5 ventro-posterior por- 

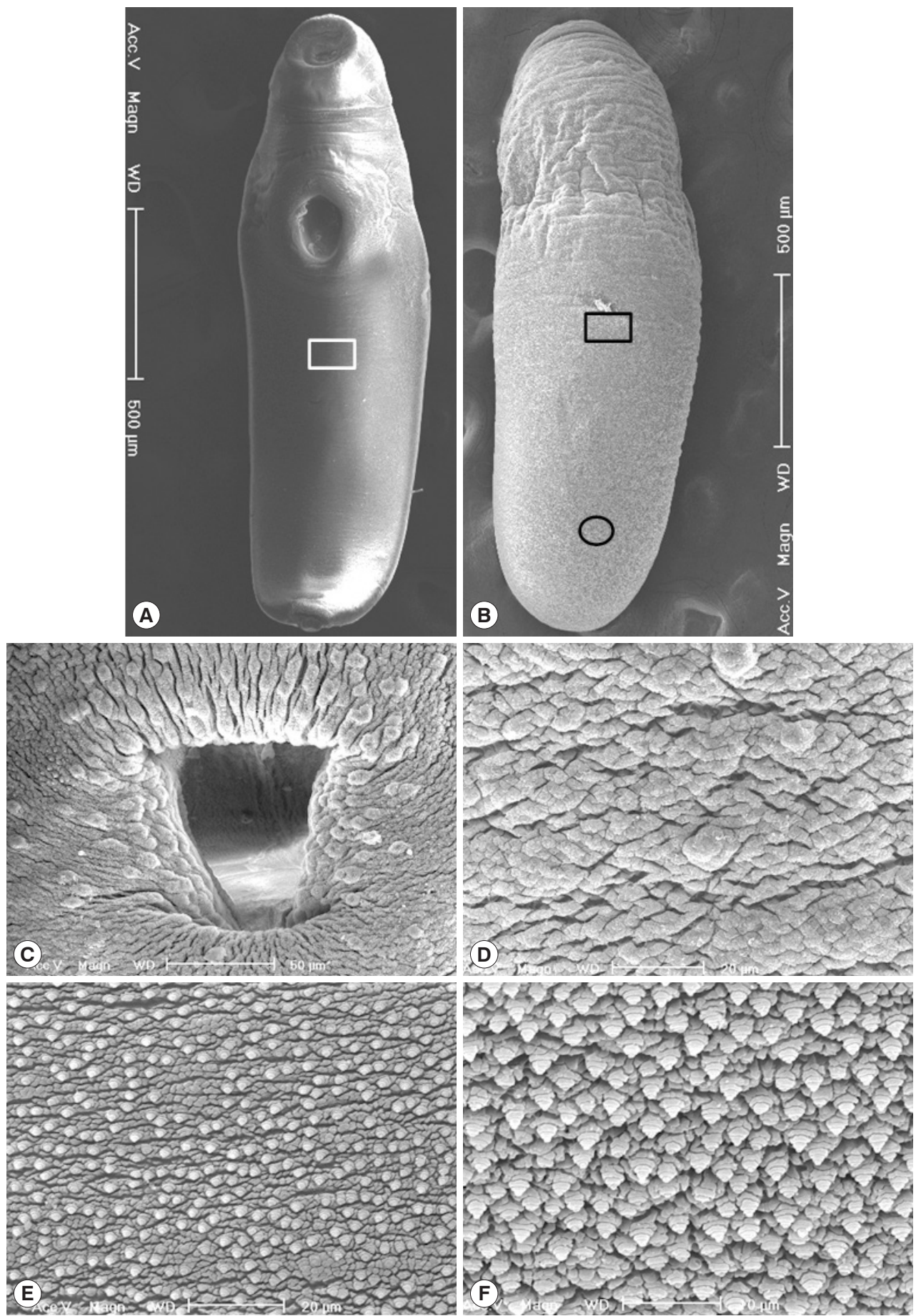

Fig. 3. Scanning electron micrographs of Korean clinostomid metacercariae collected in Carassius auratus from Nakdong-gang in Sangju-si, Gyeongsangbuk-do. (A) Whole ventral view. (B) Whole dorsal view. (C) Ventral sucker with numerous dome-shaped sensory papillae. (D) Tegumental surface on the ventro-median portion with no papillae-like spinous processes (square in Fig. 3A). (E) Tegumental surface on the dorso-median portion with numerous small spinous processes (square in Fig. 3B). (F) Tegumental surface on the dorsoposterior portion with numerous small spinous processes (encircled in Fig. 3B).

tion of the body and had several dome-shaped sensory papillae on the upper protruding portion (Fig. 4E). Laurer's canal opening observed at $1 / 4$ dorso-posterior of the body (Fig. 4F). On the anterior tegumental surface (squares in Fig. $4 \mathrm{~A}, \mathrm{~B}$ ), the 

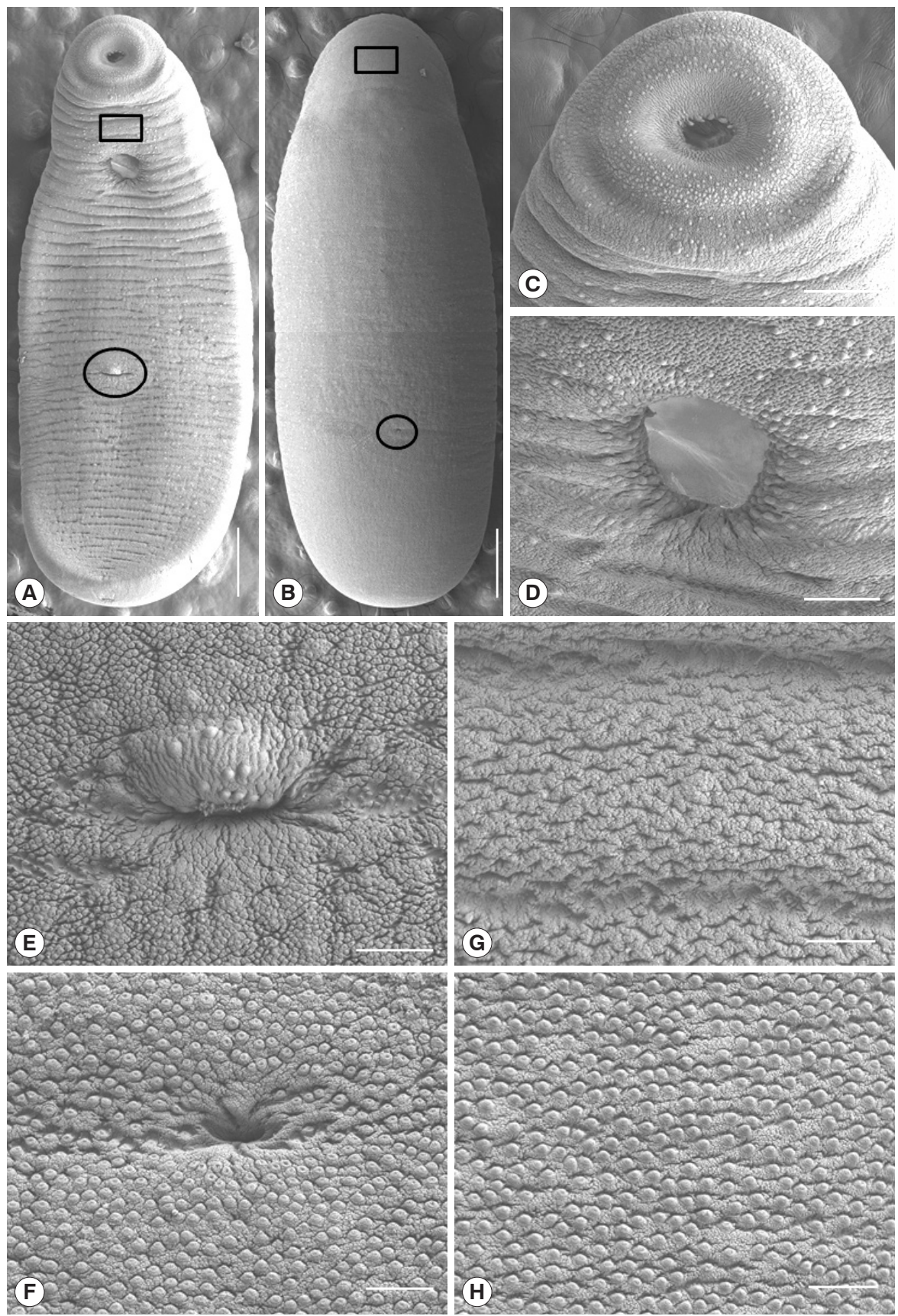

Fig. 4. Scanning electron micrographs of Myanmar clinostomid metacercariae collected in a snakehead, Channa sp., from Yangon,

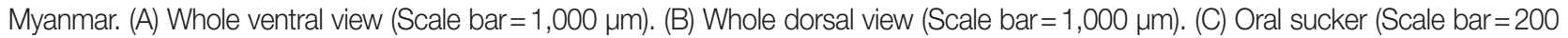
$\mu \mathrm{m})$. (D) Ventral sucker (Scale bar $=100 \mu \mathrm{m})$. (E) Tegumental surface around the genital pore (encircled in Fig. 4A) in 2/5 posterior portion of the body (Scale bar $=50 \mu \mathrm{m}$ ). (F) Tegument around the Laurer's canal (encircled in Fig. 4B) at 1/4 dorso-posterior portion of the body. (G) Tegument between the oral and ventral suckers with no papillae-like spinous processes (squares in Fig. 4A). (H) Tegumental surface on the dorso-middle portion with numerous papillae-like spinous processes, which were broadly distributed on the body surface except for anterior portion (squares in Fig. 4A, B) (Scale bar $=25 \mu \mathrm{m})$.

velvety cytoplasmic layer and dome-shaped sensory papillae were observed, but papillae-like processes were not seen (Fig. $4 \mathrm{G})$. Lots of stratified and papillae-like processes were broadly distributed on the whole tegumental surface except for the anterior portion (Fig. 4E, F, H). 

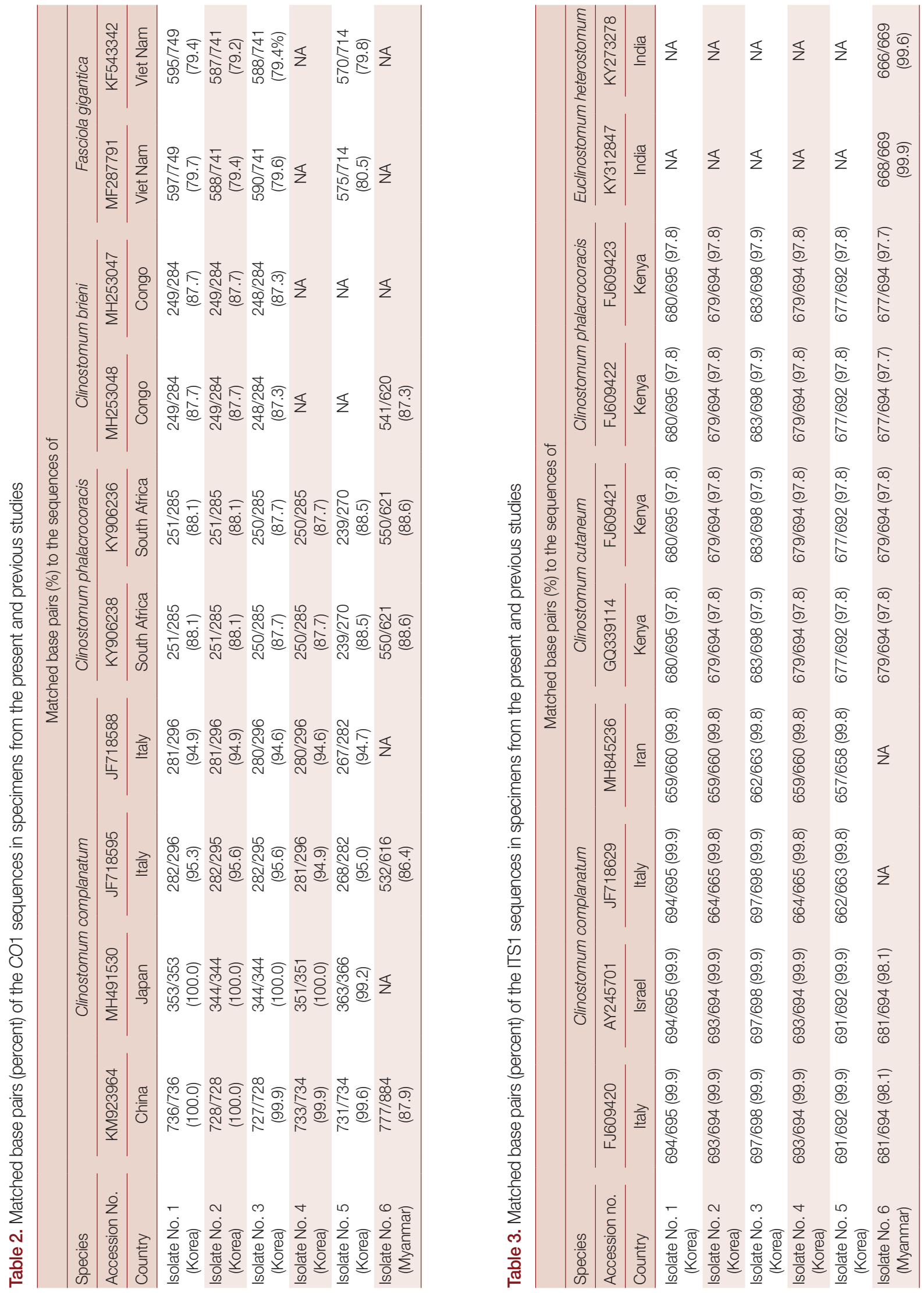


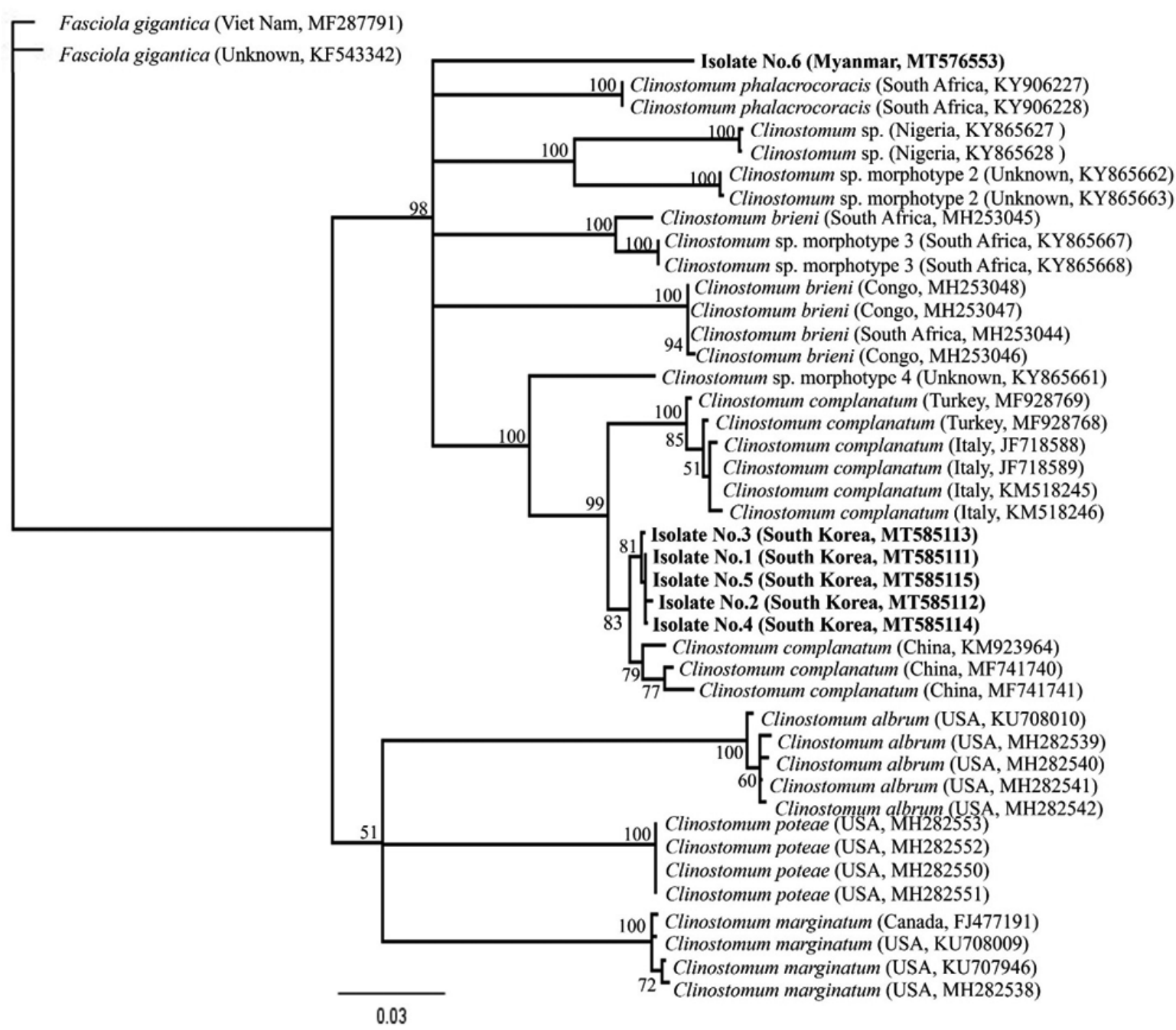

Fig. 5. Phylogenetic tree constructed based on CO1 sequences from flukes collected in this study and from platyhelminth sequences deposited in GenBank. The bootstrap values for the clade with consensus support (\%) were displayed on the tree to the left of the most recent common ancestral node for that clade. The scale bar at the bottom of the tree indicated the length of the branches of the tree.

\section{Molecular findings}

The CO1 sequences of 5 Korean specimens ranging in size from 728 to 736 bp showed $99.6-100 \%$ identity with Clinostomum complanatum (GenBank no. KM923964), but 87.7-88.5\% identity with Clinostomum phalacrocoracis (KY906238) or 87.387.7\% identity with Clinostomum brieni (MH253048), respectively (Table 2). However, a Myanmar specimen could not be correctly identified with the CO1 sequence results, showing the identity of $88.6 \%, 87.9 \%$, and $87.3 \%$ to C. phalacrocoracis (FJ609422), C. complanatum (KM923964), and C. brieni (MH253048), respectively. The ITS sequences amplified resulted in fragment size from 692 to $698 \mathrm{bp}$. The consensus sequences of the 5 Korean specimens gave 99.9-100\% identity with C. complanatum (FJ609420), but differed by $2 \%$ from $C$. phalacrocoracis (97.8-97.9\% identity with the sequence of FJ609422) or Clinostomum cutaneum (97.8-97.9\% identity with the sequence of FJ609421), respectively (Table 3). On the other hand, the ITS sequences of a Myanmar isolate sized with 694 bp showed 99.9\% identity with Euclinostomum heterostomum (KY312847), but 98.1\% identity with C. complanatum (FJ609420 and AY245701), 97.8\% identity with C. cutaneum (GQ339114 and FJ609421), or 97.7\% identity with C. phalacrocoracis (FJ609422 and FJ609423), respectively. Our 5 sequences from Korean isolates clustered with the C. complanatum CO1 genes, distinct from those of other Clinostomum species, such as $C$. phalacrocoracis, C. brieni, C. cutaneum, Clinostomum poteae, Clinostomum marginatum, or Clinostomum tataxumui (Fig. 5). We found that there was slight difference geographically, even though with- 
in the same level of species, eg., China (KM923964, MF741740, and MF741741), Italy (JF718588, JF718589, KM518245, and KM518146) or Turkey (MF928768 and MF928769), respectively. Moreover, the CO1 sequence of 1 isolate from Myanmar was far from Korean isolates, and not linked with any other sequences.

\section{DISCUSSION}

In the present study, several morphometric findings such as the size of worm body and each organ, ratio of body length to body width, and morphology of cecal lumens, in addition to the tegumental ultrastructures, were considerably different between the specimens from Korea and Myanmar. Finally, the CO1 and ITS1 sequences could confirm the Korean and Myanmar isolates as C. complanatum and E. heterostomum, respectively. Although several features such as the structure of genital complex and cirrus sac, the distance between the oral and ventral sucker and the body width, can be used to distinguish species, these structures may be variable according to developmental stages of metacercariae, host variability, and during preparation of the specimens for microscopic examinations [23]. The current study also found that there was morphological intraspecific diversity in C. complanatum. Previous researchers also experienced the same problems in the identification of the larval (metacercariae) stage which has less morphological characteristics than adults [24]. Our data also supported that there was morphological intraspecific diversity in C. complanatum, highlighting the utility of molecular approaches about $C$. complanatum.

In this study, 3 types of Korean CMc were somewhat smaller than Myanmar CMc, but they were larger and/or similar in size with CcMc previously reported in Korea and Japan [9,25, 26]. However, the morphometric indices, i.e., the ratio of $\mathrm{BL} /$ BW, VSW/OSW and VSW/BW, were similar between Type A and Type B, and between Type $\mathrm{C}$ and Myanmar CMc. The ratios of BL/BW were 3.73 and 3.89 in Type A and Type B, but 2.26 and 2.78 in Type $C$ and Myanmar CMc. The ratios of VSW/OSW were 2.09 and 2.06 in Type A and Type B, but 2.22 and 2.21 in Type $\mathrm{C}$ and Myanmar CMc. The ratios of VSW/BW were 0.54 and 0.54 in Type A and Type B, but 0.41 and 0.43 in Type $\mathrm{C}$ and Myanmar CMc. Nevertheless, the cecal lumens of Korean $\mathrm{CMc}$, thin-walled and folded, were obviously different from those of Myanmar CMc, thick-walled and bilaterally branched. On the other hand, fluke members in the family Clinostomidae are commonly residing in the buccal cavity and esophagus of animals. Among them, members in the subfamily Euclinostominae and Clinostominae are morphologically similar and commonly found in the buccal cavity and esophagus of birds (occasionally mammals). They are differentiated by the morphology of ceca with or without lateral branches and diverticula [27]. The differential key, i.e., cecal morphology, between the 2 subfamilies in the family Clinostomidae has been reconfirmed in the present study.

There have been different opinions on the presence of tegumental spines in CcMc from Japan and Korea. Aohagi and Shibahara [26] described the minute single spines covering the body surface of CcMc in Japan, but Chung et al. [9] reported that distinct spines were not observed on the tegument of CcMc in Korea. In our SEM study, lots of stratified spinous processes with a single tip were observed on the whole dorsal tegumental surface of CcMc from Korea. Meanwhile, numerous stratified and papillae-like processes were broadly distributed on the whole tegumental surface except for the anterior portion in the E. heterostomum metacercariae from Myanmar. In the SEM observations of E. heterostomum metacercariae from guppy, Poecilia reticulata, which were experimentally infected with cercariae in Thailand, the tegumental ultrastructures were smooth and obscure in detail [30]. At any rate, it was confirmed that the tegumental spines are present in clinostomid, C. complanatum and E. heterostomum, metacercariae, although their shape and distribution patterns are more or less different.

The metacercariae of E. heterostomum were detected in fish hosts from several geographical regions [28-32]. Especially, they were also found in fish from Thailand and India, the adjacent countries of Myanmar [30-32]. The morphometric and molecular characteristics of E. heterostomum metacercariae, which were detected in the cichilid fish from Lake Kinneret in Israel, were described by Caffara et al. [28]. The metacercariae (av. 6,287 $\times 3,015$ ) from Israel were more or less smaller and stouter than those from Myanmar (av. 7,675×2,778) in this study. The ratios of BL/BW (2.10 and 2.78) and VSW/BW (0.45 and 0.43 ) were similar between $E$. heterostomum metacercariae from Israel and Myanmar. However, the ratios of VSW/OSW (1.66 and 2.21) and branching severities of ceca and sizes of cecal branches were somewhat different between those from Israel and Myanmar.

In general, ITS and CO1 are commonly used to infer species boundaries and relationships in flatworms [18-20]. In the current study, 5 Clinostomum isolates (Isolate No. 1-5) were correctly identified as $C$. complanatum, differentiated from the 
other Clinostomum species harboring significant difference more than $10 \%$. Interestingly, the intraspecific genetic distances between our isolates and other $C$. complanatum isolates deposited from the various geographical areas in GenBank displayed variation more or less $5 \%$. Indeed, we also found that the low level of variation (within 2\%) in ITS between Clinostomum species (C. complanatum, C. cutaneum, C. phalacrocoracis) and this may not be sufficient for discriminating species of Clinostomum without morphological support. Even the species described based on unreliable characters may turn out to be genetically distinct and valid, particularly in cases where types were obtained in different biogeographic regions [24]. Meanwhile, the $\mathrm{CO} 1$ sequences of a Myanmar isolate were not correctly matched with those of Clinostomum species (less than $89 \%$ identity). We could not find any genetic information matched with the $\mathrm{CO} 1$ sequence of Myanmar isolate, showing even more than $90 \%$ identity in the GenBank database. Finally, however, the Myanmar isolate could be identified as E. heterostomum by an aid of ITS sequencing. In addition, we could firstly enroll the $\mathrm{CO} 1$ sequence of $E$. heterostomum to the GenBank database. Collectively, we support that the mitochondrial markers seem insufficient for discrimination of the Clinostomum species and their database should be enforced and expanded further.

Conclusively, we described the morphological and molecular characteristics of Korean clinostomid isolates compared to those of a Myanmar isolate. Based on these characteristics, 5 clinostomid metacercariae collected from Korea were demonstrated as C. complanatum, whereas the Myanmar isolate as E. heterostomum. Our morphological and molecular data can provide a useful point of reference for future studies regarding clinostomid isolates.

\section{ACKNOWLEDGMENTS}

We appreciate Jung-A Kim and Hee-Ju Kim in the Department of Parasitology and Tropical Medicine, Gyeongsang National University College of Medicine, Jinju, Korea for their help in examination of fish. This work was partially supported by the Basic Science Research Program through the National Research Foundation of Korea (NRF) funded by the Ministry of Education (NRF-2019R1C1C1004605; NRF-2019M3E5D1A02067953). The funders had no role in the study design, data collection, and analysis decision to publish or preparation of the manuscript.

\section{CONFLICT OF INTEREST}

The authors have no conflicts of interest concerning the work reported in this paper.

\section{REFERENCES}

1. Kitagawa N, Oda M, Totoki T, Washizaki S, Oda M, Kifune T. Lidocaine spray used to capture a live Clinostomum parasite causing human laryngitis. Am J Otolaryngol 2003; 24: 341-343. https:// doi.org/10.1016/s0196-0709(03)00060-7

2. Hara H, MiyauchiY, Tahara S, Yamashita H. Human laryngitis caused by Clinostomum complanatum. Nagoya J Med Sci 2014; 76 181-185

3. Chung DI, Moon CH, Kong HH, Choi DW, Lim DK. The first human case of Clinostomum complanatum (Trematoda: Clinostomidae) infection in Korea. Korean J Parasitol 1995; 33: 219223. https://doi.org/10.3347/kjp.1995.33.3.219

4. Park CW, Kim JS, Joo HS, Kim J. A human case of Clinostomum complanatum infection in Korea. Korean J Parasitol 2009; 47: 401-404. https://doi.org/10.3347/kjp.2009.47.4.401

5. Jung SC, Oh HJ, Kim DM, Park JH. A case of pharyngitis caused by Clinostomum complanatum. Korean J Otorhinolaryngol-Head Neck Surg 2015; 58: 61-63 (in Korean). https://doi.org/10.3342/ kjorl-hns.2015.58.1.61

6. Lee GS, Park SW, Kim J, Seo KS, You KW, Chung JH, Moon HC, Hong GY. A case of endoscopically treated laryngopharyngitis resulting from Clinostomum complanatum infection. Korean J Gastroenterol 2017; 69: 177-180. https://doi.org/10.4166/kjg.2017.69. 3.177

7. Song HB, Choi MH, Chung EJ. Human laryngeal infection by Clinostomum complanatum. Am J Trop Med Hyg 2018; 98: 7-8. https://doi.org/10.4269/ajtmh.17-0718

8. Kim HJ, Cho SW, Oh HR, Byeon HK. A case of unexpected Clinostomum complanatum infection initially presenting as foreign body in pharynx. Korean J Parasitol 2019; 57: 175-177. https://doi.org/10.3347/kjp.2019.57.2.175

9. Chung DI, Kong HH, Moon CH. Demonstration of the second intermediate hosts of Clinostomum complanatum in Korea. Korean J Parasitol 1995; 33: 305-312. 10.3347/kjp.1995.33.4.305

10. Chung DI, Kong HH, Joo CY. Radix auricularia coreana: natural snail host of Clinostomum complanatum in Korea. Korean J Parasitol 1998; 36: 1-6. https://doi.org/10.3347/kjp.1998.36.1.1

11. Rim HJ, Kim KH, Joo KH, Kim SJ, Eom KS, Chung MS. The infestation status and changing patterns of human infecting metacercariae in freshwater fish in Kyongsang-do and Kyonggi-do, Korea. Korean J Parasitol 1996; 34: 95-105. https://doi.org/10.3347/ kjp.1996.34.2.95

12. Sohn WM, Na BK, Cho SH, Lee SW, Choi SB, Seok WS. Trematode metacercariae in freshwater fish from water systems of Hantangang and Imjingang in Republic of Korea. Korean J Parasitol 2015; 53: 289-298. https://doi.org/10.3347/kjp.2015.53.3.289 
13. Sohn WM, Na BK, Cho SH. Infection status with Clinostomum complanatum metacercariae in fish from water systems of Nakdonggang (River) in Korea. Korean J Parasitol 2019; 57: 389-397. https:// doi.org/10.3347/kjp.2019.57.4.389

14. Ukoli FM. (1966). On Clinostomum tilapiae n. sp., and C. phalacrocoracis Dubois, 1931 from Ghana, and a discussion of the systematics of the genus Clinostomum Leidy, 1856. J Helminthol 1966; 40: 187-214. https://doi.org/10.1017/s0022149x00034192

15. Feizullaev NA, Mirzoeva SS. Revision of the superfamily Clinostomoidea and analysis of its system. Parazitologiya 1983; 17: 3-11 (in Russian).

16. Matthews D, Cribb TH. Digenetic trematodes of the genus Clinostomum Leidy, 1856 (Digenea: Clinostomidae) from birds of Queensland, Australia, including C. wilsoni n. sp. from Egretta intermedia. Syst Parasitol 1998; 39: 199-208.

17. Dzikowski R, Levy MG, Poore MF, Flowers JR, Paperna I. Clinostomum complanatum and Clinostomum marginatum (Rudolphi, 1819) (Digenea: Clinostomidae) are separate species based on differences in ribosomal DNA. J Parasitol 2004; 90: 413-414. https://doi. org/10.1645/GE- 159R

18. Nolan MJ, Cribb TH. The use and implications of ribosomal DNA sequencing for the discrimination of digenean species. Adv Parasitol 2005; 60: 101-163. https://doi.org/10.1016/S0065-308X(05) 60002-4

19. Locke SA, McLaughlin JD, Dayanandan S, Marcogliese DJ. Diversity and specificity in Diplostomum spp. metacercariae in freshwater fishes revealed by cytochrome $c$ oxidase I and internal transcribed spacer sequences. Int J Parasitol 2010; 40: 333-343. https://doi.org/10.1016/j.ijpara.2009.08.012

20. Caffara M, Locke SA, Gustinelli A, Marcogliese DJ, Fioravanti ML. Morphological and molecular differentiation of Clinostomum complanatum and Clinostomum marginatum (Digenea: Clinostomidae) metacercariae and adults. J Parasitol 2011; 97: 884-891. https:// doi.org/10.1645/ GE-2781.1

21. Sohn WM, Na BK, Cho SH Lee SW. Infection status with digenetic trematode metacercariae in fishes from coastal lakes in Gangwon-do, Republic of Korea. Korean J Parasitol 2019; 57: 681-690. https://doi.org/10.3347/kjp.2019.57.6.681

22. Won EJ, Kim DG, Cho J, Jung BK, Kim MJ, Yun YW, Chai JY, Ryang DW. Molecular description of Macroorchis spinulosus (Digenea: Nanophyetidae) based on ITS1 sequences. Korean J Parasitol 2016; 54: 109-112. https://doi.org/10.3347/kjp.2016.54.1.109
23. Luton K, Walker D, Blair D. Comparisons of ribosomal internal transcribed spacers from two congeneric species of flukes (Platyhelminthes: Trematoda: Digenea). Mol Biochem Parasitol 1992; 56: 323-327. https://doi.org/10.1016/0166-6851(92)90181-i

24. Simsek E, Yildirim A, Yilmaz, E, Inci A, Duzlu O, Onder Z, Ciloglu A, Yetismis G, Pekmezci GZ. Occurrence and molecular characterization of Clinostomum complanatum (Trematoda: Clinostomidae) in freshwater fishes caught from Turkey. Parasitol Res 2018; 117: 2117-2124. https://doi.org/10.1007/s00436018-5898-3

25. Kagei N, Yanohara Y, Uchikawa R, Sato S. On the yellow grubs, metacercariae of Clinostomum complanatum (Rudolphi, 1819), found in the cultured loach. Jpn J Parasitol 1984; 33: 59-62.

26. Aohagi Y, Shibahara T. Clinostomum complanatum infection in Carassius spp. collected from some ponds and rivers in Tottori and Shimane Prefecture, Japan. Jpn J Parasitol 1994; 43: 129135.

27. Kanev I, Radev V, Fried B. Family Clinostomidae Lu“he, 1901. In Gibson DI, Jones A, Bray RA eds, Keys to the Trematoda. Vol. 1. Wallingford, UK. CAB International, the Natural History Museum. 2002, pp 113-120.

28. Caffara M, Locke SA, Cristanini C, Davidovich N, Markovich MP, Fioravanti ML. A combined morphometric and molecular approach to identifying metacercariae of Euclinostomum heterostomum (Digenea: Clinostomidae). J Parasitol 2016; 102: 239-248. https://doi.org/10.1645/15-823

29. Echi P, Eyo J, Okafor F, Onyishi G, Ivoke N. First record of co-infection of three clinostomatid parasites in cichlids (Osteichthyes: Cichlidae) in a tropical freshwater lake. Iran J Public Health 2012; 41: 86-90.

30. Suanyuk N, Mankhakhet S, Soliman H, Saleh M, El-Matbouli M. Euclinostomum heterostomum infection in guppies Poecilia reticulata cultured in southern Thailand. Dis Aquat Org 2013; 104: 121127. https://doi.org/10.3354/dao02595

31. Senapin S, Phiwsaiya K, Laosinchai P, Kowasupat C, Ruenwongsa P, Panijpan B. Phylogenetic analysis of parasitic trematodes of the genus Euclinostomum found in Trichopsis and Betta fish. J Parasitol 2014; 100: 368-371. https://doi.org/10.1645/13-285.1

32. Athokpam VD, Tandon V. A survey of metacercarial infections in commonly edible fish and crab hosts prevailing in Manipur, Northeast India. J Parasit Dis 2015; 39: 429-440. https://doi. org/10.1007/s12639- 013-0360-Z 
